\title{
Measured and Perceived Physical Fitness, Intention, and Self-Reported Physical Activity in Adolescence
}

\author{
Timo Jaakkola ${ }^{1}$, Tracy L. Washington ${ }^{2}$ \\ ${ }^{1}$ Department of Sport Sciences, University of Jyväskylä, Jyväskylä, Finland; \\ ${ }^{2}$ School of Exercise and Nutrition Sciences, IHBI, Faculty of Health, Queensland University of Technology, \\ Brisbane, Australia. \\ Email: timo.jaakkola@jyu.fi \\ Received September 16 $6^{\text {th }}, 2011$; revised October 19 $9^{\text {th }}, 2011$; accepted October $29^{\text {th }}, 2011$.
}

\begin{abstract}
Objective: The aim of this study was to investigate the associations among measured physical fitness, perceived fitness, intention towards future physical activity and self-reported physical activity through junior high school years. Methods: Study participants included 122 Finnish students who were 13 years old during Grade 7 . The sample was comprised of 80 girls and 42 boys from 3 junior high schools (Grades 7 - 9). During the autumn semester of Grade 7, students completed fitness tests and a questionnaire analyzing self-perception of their physical fitness. The questionnaire delivered at Grade 8 included intention towards future physical activity. At Grade 9 students' self-reported physical activity levels. Results: Structural Equation Modelling revealed an indirect path from physical fitness to self-reported physical activity via perceived physical fitness and intention towards future physical activity. The model also demonstrated a correlation between perceived physical fitness and physical activity. Squared multiple correlations revealed that perceived physical fitness explained $33 \%$ of the actual physical fitness. Conclusions: The results of this study highlight the role of physical and cognitive variables in the process of adoption of physical activity in adolescence.
\end{abstract}

Keywords: Physical Activity, Fitness, Self-Perceptions, Adolescents

\section{Introduction}

Childhood and adolescence is a critical time period for adopting a physically active lifestyle. Evidence exists to demonstrate that childhood and adolescence patterns of physical activity (PA) moderately track into adulthood which means that active children and adolescents are more likely to become active adults (Telama et al., 2005). Additionally, previous studies have shown that PA declines markedly during the transition from elementary school to secondary school and the decrease continues throughout secondary school (Telama \& Yang, 2000; Nader, Bradley, \& Houts, 2008). This decline is suggested to be related with different physical, psychological, and social factors (Sallis, Prochaska, \& Taylor, 2000). Aforementioned studies demonstrate that investigating the antecedents of youth PA patterns remain one of the most important topics in the sport sciences.

The concept of physical fitness can be divided into healthrelated fitness and skill related fitness (Caspersen, Powell, \& Christenson, 1985). Health related fitness includes the components of cardiorespiratory endurance, muscular endurance, muscular strength, body composition, and flexibility. Skillrelated fitness includes factors such as agility, balance, coordination, speed, power, and reaction time. Methods analyzing physical fitness within children and adolescents typically involve both fitness themes (Safrit, 1990). It has been suggested that physical fitness in childhood and adolescence is an important factor influencing engagement of PA in adulthood (Malina, 2001). More specifically, research has shown that youth who are more active, obtain higher scores on cardiovascular tests than inactive youth when compared with inactive youths. However, the associations between other health-related fitness variables and PA are more inconsistent (Huotari, Nupponen, Laakso, \& Kujala, 2009; Huotari, Nupponen, Laakso, \& Kujala, 2010).
A number of social-cognitive models hypothesize that different cognitive variables are involved in the process of adopting behaviors such as .PA engagement (Ajzen, 1991; Bandura, 1997; Hagger \& Chatzisarantis, 2007). These cognitive attributes include physical self-perceptions and intention towards future activity. More specifically, studies have shown that self-perceptions such as perceived physical competence (Bagoien \& Halvari, 2005), self-efficacy (Dishman et al., 2005), and self-esteem (Tremblay, 2000) have been positively associated with PA in school aged participant groups. Additionally, many socialcognitive theories have suggested that there are cognitive processes determining behavior. One of the most utilized social cognitive theories in the field of PA research is the theory of planned behavior (TPB), which postulates that belief-based social cognitive constructs, namely attitudes, subjective norms and perceived behavioral control, are antecedents of behavior such as PA (Ajzen, 1991). Attitudes in TPB are defined as a person's belief that the target behavior will result in certain desirable outcomes. Subsequently, subjective norms are defined as a person's belief that others desire them to perform the target behavior. Perceived behavioral control in TPB represents a person's belief that they have capacities, faculties, abilities, and resources to engage in the target behavior. Conceptually perceived behavioral control of the theory of planned behavior represents a rather similar construct than self-efficacy (Bandura, 1997) and perceived competence (Harter, 1978) in other social-cognitive models. All of these constructs assume that the belief a person has on their abilities and capacities effects their subsequent behavior. The link between physical self-perceptions and PA has been shown in many studies using the samples of schoolchildren (Hagger \& Chatzisarantis, 2009; Hagger, Chatzisarantis, Biddle, \& Orbell, 2001; Hagger, Chatzisarantis, Culverhouse, \& Biddle, 2003; Sallis et al., 2000). In the present study, we use the variable of perceived physical fitness to rep- 
resent perceived competence related to the person's actual physical fitness (see Figure 1). Theoretically, we assume that the variable of perceived physical fitness represents a similar construct rather than perceived behavioral control in the theory of planned behavior.

Interestingly, previous studies have shown that children and adolescents have rather reliable perceptions of their measured physical fitness (Huotari, Sääkslahti, \& Watt, 2009). For example, Huotari et al. (2009) reported high correlations between measured and perceived fitness in a sample of 48 Finnish 12 year-old children. Specifically, the correlations between measured and perceived endurance and strength was .69 and .71 respectively. These results indicate that Finnish children perceive his/her own physical fitness as a reliable representation of actual fitness. In the other words, the objective measure of fitness seems to determine whether children perceive themselves competent in situations related to physical fitness. Although the evidence on the association among measured physical fitness, physical self-perceptions, and PA exist, there are no studies analyzing the interaction between measured and perceived fitness in the process of adopting PA.

Social-cognitive models suggest that intention mediates the association between self-perceptions and behavior (Ajzen, 1991; Hagger \& Chatzisarantis, 2007). Therefore, intention is observed as the most reliable and proximal predictor of behavior. Conceptually, intention is intended to summarize a person's general affective and cognitive orientation toward the behavior, the perceived pressure placed on them by significant others to participate in the target behavior and their competence-related evaluation of their faculties and capacities toward the behavior (Hagger et al., 2003). According to the TPB and the transcontextual model, intention is a direct predictor of behavior, whereas physical self-perceptions represent indirect predictors (Hagger et al., 2003; Hagger, Chatzisarantis, \& Harris, 2006). The studies within the context of PA have supported this assumption of the mediating role of intention between self-perceptions and behavior (Hagger \& Chatzisarantis, 2009; Lippke, Ziegelmann, \& Schwarzer, 2004). Intention is considered to be an important factor in the process of adopting the habit of PA. However, there are only a few studies to investigate the relationship between intention toward activity and PA within adolescent groups (Hagger et al., 2001; Hagger et al., 2003; Hagger et al., 2007). Furthermore, the observed studies were longitudinal where only a few weeks time interval was allowed to investigate how cognitive variables would translate into behavior. Behavioral change is a complex process and therefore we can assume that the process takes more time (Booth et al., 2010).

The rationale of the current study stems from the theoretical predictions and empirical results presented above. We assume that the measured physical fitness variables will result in perceived physical fitness, which subsequently fall within the intention to be physically active. The intention would then result in physical activity later. In the other words, we suggest that there are sequential associations among measured and perceived physical fitness, intention toward PA, and self-reported PA. In this study, we test these associations through junior high school years by measuring fitness and perceived physical fitness variables at Grade 7 as the first variables in the model. Intention toward future activity is gathered at Grade 8 and is set as the second variable in the model, and the last variable located in the model is self-reported PA which is collected and analyzed at Grade 9. To our knowledge, this is the first study to analyze the relationship among these four variables in the same model through the adolescent years. Research is needed in this area as previous studies have demonstrated that PA clearly declines within the adolescent years (Telama \& Yang, 2000; Nader et al., 2008) and that PA adopted in childhood and adolescence is known to track into adulthood (Telama et al., 2005).

Hence, the primary aim of this study was to investigate the associations among measured physical fitness, perceived fitness, intention towards future PA, and self-reported PA during the junior high school years. We hypothesized that physical fitness would be positively associated with perceived physical fitness at Grade 7. Additionally, we assumed that perceived physical fitness would positively and sequentially predict intention towards PA at Grade 8 and self-reported PA at Grade 9. The sequential pattern of study variables is presented in Figure 1.

\section{Methods}

\section{Participants and Design of the Study}

Study participants included 122 Finnish students who were 13 years old during their Grade 7. The sample was comprised of 80 girls and 42 boys from 3 junior high schools (grades 7 - 9). During the autumn semester of Grade 7 students implemented the fitness tests and completed the questionnaire analyzing self-perception of their physical fitness. The questionnaire delivered at Grade 8 included intention towards future PA. Within Grade 9 students' self-reported PA engagement was collected.

\section{Instruments}

Fitness tests. The physical fitness tests package is a widely used instrument in Finnish physical education (Nupponen, Soini, \& Telama, 1999). Throughout junior high school, the test package is typically implemented one or two times every aca-

$$
\begin{array}{llll}
\text { Grade } 7 & \text { Grade } 7 & \text { Grade } 8 & \text { Grade } 9
\end{array}
$$

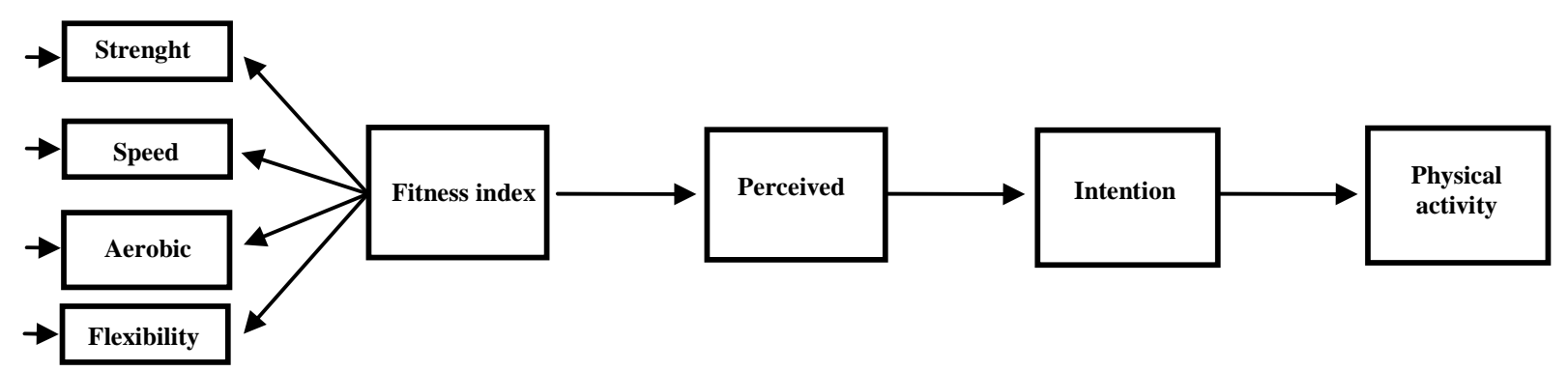

Figure 1.

The hypothesized sequential pattern of associations among the study variables. 
demic year. The primary aim of the fitness tests is to give students information on their physical fitness levels and to motivate them to exercise during their leisure time. The Finnish test package includes items analyzing students' strength, speed, aerobic fitness, flexibility, and fundamental movement skills. For the purpose of this study, we used only the items pertaining to strength, speed, aerobic fitness, and flexibility. It should be noted that there are two parallel aerobic fitness and abdominal muscle endurance tests in the Finnish physical education fitness test package. Girls typically run 1500 meters for the aerobic fitness test, whereas boys favor the 12 minute Cooper test. In this study, all girls participated in the 1500 meter test and most of the boys $(76 \%)$ completed the Cooper test. The manual also includes two abdominal tests analyzing abdominal muscle endurance. The first is a 30 seconds sit up test and the second is a Curl-up test.. All physical fitness tests in this study were implemented according to the international and Finnish standards for the assessment of physical fitness (Eurofit, 1988; Larson, 1974; Nupponen et al., 1999; Safrit 1990). These tests are valid and reliable tools in measuring junior high school aged children's' physical fitness.

The instruments analyzing perceived physical fitness, intention towards future PA, and self-reported PA were adopted from the Health Behavior in School-aged Children survey, which was developed by the World Health Organization and is conducted in North America and many countries within Europe. Prochaska, Sallis and Long (2001) reported adequate factorial validity and reliability of these two PA engagement items in a sample of 148 adolescents.

Abdominal muscle endurance tests. The goal of the $30 \mathrm{sec}$. abdominal muscle test is to complete as many sit-ups in 30 seconds as possible. In the Curl-up test participants are required to perform the task at a given pace at five second intervals and effectively complete as many repetitions as possible. In the 30 sec. test, the participant's hands are crossed behind their head, whereas in the Curl-up test, hands are crossed in front of the trunk fingers being on shoulders. In $30 \mathrm{sec}$. test, the result is the amount of proper repetitions within 30 second time. In the latter abdominal test, the result is the number of proper repetitions which the person can perform on pace.

Speed test. In the speed test, the purpose was to run 50 meters as quick as possible. The student started running from ready - go signals and a teacher recorded the running time by stopwatch. The result is the total running time from the start signal to the crossing of the finish line.

Aerobic fitness tests. Aerobic fitness was assessed by the 1500 meters running test and $12 \mathrm{~min}$. Cooper test. The result of the 1500 meters test is the total time for running the distance. In the Cooper test, the result is the amount of meters, which a person was able to run within 12 minutes.

Flexibility test. Sit and reach test was used in analyzing students' flexibility. In the test, the task is to sit on the floor both legs straight against a bench and reach forward. The meter is spread out on the bench so that the result is $50 \mathrm{~cm}$ if the student is able to reach fingertips at the level of his/her soles.

Perceived physical fitness. Perceived physical fitness was measured by a one item question, "How do you consider your physical fitness?" The item is presented using a 4-point response scale $(1=$ Poor, 2 = Moderate, $3=$ Good, $4=$ Excellent $)$.

Intention towards future physical activity. Intention towards future PA was analyzed by the question: "How likely are you to participate in regular PA after one year". The item is rated on a five point Likert scale $(1=$ strongly unlikely to $5=$ strongly likely).
Self-reported physical activity. PA engagement was analyzed by a self-report questionnaire. The introduction for the questions is: "In the next two questions PA means all activities which raise your heart rate or momentarily gets you out of breath, for example, in doing exercise, playing with your friends, going to school, or in school physical education. PA also includes for example jogging, intensive walking, roller skating, cycling, dancing, skating, skiing, soccer, basketball and baseball." The items are "Think about your typical week. How many days did you exercise for at least $60 \mathrm{~min}$. during which you got out of breath" and "Think about your last 7 days. How many days did you exercise for at least $60 \mathrm{~min}$ during which you get out of breath?" Both items are presented using an 8-point response scale, 0 to 7 days in a week. A sum scale of PA engagement was formulated by adding the response scores for the two items to assess students' self-reported engagement in both moderate to vigorous and vigorous PA.

\section{Data Preparation}

Numerous steps were taken to prepare for the data analysis. It should be noted that the scales in this study were originally in the reverse direction when compared with the other instruments. Therefore, for the clarity of results in correlation and structural equation modelling (SEM) analyses we transformed the two scales to be comparable with the other measures. Additionally, before SEM analysis was conducted, the abdominal test (the 30 sec. sit-up and Curl-up test) scores were summed together to create a sumscale. Furthermore, the same procedure was followed for the two aerobic fitness test scores. Subsequently, actual scores were then translated as standardized Z-scores for further statistical analyses. Finally, exogenous or indirectly observed variables of strength, speed, aerobic fitness, and flexibility were identified as a latent variable of fitness for the SEM analyses.

\section{Data Analysis}

The participants' scores for both the fitness tests and the self-report questionnaires were summarized using descriptive statistics. Pearson's correlation coefficients and structural equation modelling were used to examine the relationships between variables. Statistical analyses were conducted using PASW for Windows 18 (yr) and LISREL 8.30 (yr) software. In the fitness data, altogether 96 students completed the $30 \mathrm{sec}$. abdominal muscle endurance test, and twenty-five students completed the abdominal curl up muscle test. For the aerobic fitness tests 90 students ran the timed 1500 meters and 32 students completed the Cooper test.

\section{Results}

The descriptive data of measured variables are shown in Table 1. Pearson's correlation coefficients are shown in Table 2 indicate that significant moderate correlations exist among strength, speed, and aerobic fitness. The correlations between flexibility and other physical fitness variables were weak. Additionally, perceived physical fitness, intention towards, future activity, strength, speed, and aerobic fitness had weak to moderate intercorrelations. PA correlated significantly only with strength, perceived physical fitness, and intention towards future activity; however, these correlations were weak.

The adequacy of the hypothesized model of study variables were analyzed via structural equation modelling (SEM). Firstly, descriptive statistics were analyzed and results indicated that the scales were approximately normally distributed. Therefore, the 
maximum likelihood method was applied. The overall fit of the analyzed model to the data was investigated using the chi-square test $\left(\mathrm{x}^{2}\right)$. A non-significant result shows that the proposed model has an acceptable fit to the data. Additionally, the Root Mean Square Error of Approximation (RMSEA), the Non Normed Fit Index $(N N F I)$, the Goodness of Fit Index $(G F I)$, and the Adjusted Goodness of Fit Index ( $A G F I$ ) were examined. The NNFI, $G F I$, and $A G F I$ indices vary from 0 to 1 . Fit indices greater than 0.90 are indicative of acceptable model fit. In addition, the $p$-value associated with a hypothesis test of RMSEA of $\leq 0.05$ is indicative of a representative model. Additionally, the proportion of variance predicted by independent variables for the dependent variables were investigated using squared multiple correlations $\left(r^{2}\right)$.
The results of the proposed model demonstrated poor fit to the data. The next phase was to examine the modification indices and remove all insignificant path coefficients from the model. After this procedure SEM analysis revealed that the final model had a good fit to the data $\left(\mathrm{x}^{2}=[12]=9.78, p>0.71 ; N N F I=\right.$ $1.00 ; G F I=0.98 ; A G F I=95 ; R M S E A=0.000)$.

The model reveals an indirect path from physical fitness index to self-reported PA via perceived physical fitness and intention towards future PA. The model also demonstrated a correlation between perceived physical fitness and PA. Squared multiple correlations revealed actual physical fitness explained rather highly perceived physical fitness (33\%). All other squared multiple correlations are low. The final model is presented in Figure 2.

Table 1 .

Variables of the study (Grades 7 - 9).

\begin{tabular}{lcccccc}
\hline \multicolumn{1}{c}{ Variable } & $\mathrm{n}$ & Grade & $\mathrm{M}$ & $\mathrm{SD}$ & Min & Max \\
\hline 30 sec. abdom. test (repetitions) & 97 & 7 & 23.04 & 6.43 & 9 & 43 \\
Curl up abdom. test (repetitions) & 25 & 7 & 123.85 & 69.36 & 33 & 220 \\
50 m speed test (sec.) & 122 & 7 & 8.48 & 0.76 & 7.22 & 10.03 \\
Cooper test (meters) & 32 & 7 & 2196.72 & 362.05 & 1540 & 2650 \\
1500 m test (min. sec.) & 90 & 7 & 8.14 & 1.17 & 6.00 & 13.17 \\
Reaching test (cm) & 122 & 7 & 61.38 & 8.39 & 30 & 78 \\
Perceived fitness & 122 & 7 & 2.90 & 0.66 & 1 & 4 \\
Intention & 122 & 8 & 4.43 & 0.87 & 1 & 5 \\
Physical activity & 122 & 9 & 3.96 & 1.71 & 0 & 7 \\
\hline
\end{tabular}

Table 2.

Correlations among the study variables.

\begin{tabular}{lllllll}
\hline & 1. & 2. & 3. & 4. & 5. & 6. \\
\hline 1. Strength & - & & & & & \\
2. Speed & $0.39^{* * *}$ & - & & & & \\
3. Aerobic fitness & $0.40^{* * *}$ & $0.62^{* * *}$ & - & & & \\
4. Flexibility & 0.09 & 0.17 & $0.19^{*}$ & - & & \\
5. Perceived fitness & $0.30^{* * *}$ & $0.34^{* * *}$ & $0.38^{* * *}$ & 0.10 & - & \\
6. Intention & $0.31^{* * *}$ & $0.20^{*}$ & $0.32^{* * *}$ & 0.07 & $0.35^{* * *}$ & - \\
7. Physical activity & $0.23^{* *}$ & 0.02 & 0.13 & 0.01 & $0.32^{* * *}$ & $0.26^{* *}$ \\
$p<0.05^{*}, p<0.01^{* *}, p<0.001^{* * *}$ & & & & & & \\
\hline & \multicolumn{7}{c}{ Grade 7 } & & Grade 7 & & Grade 8 & Grade 9
\end{tabular}

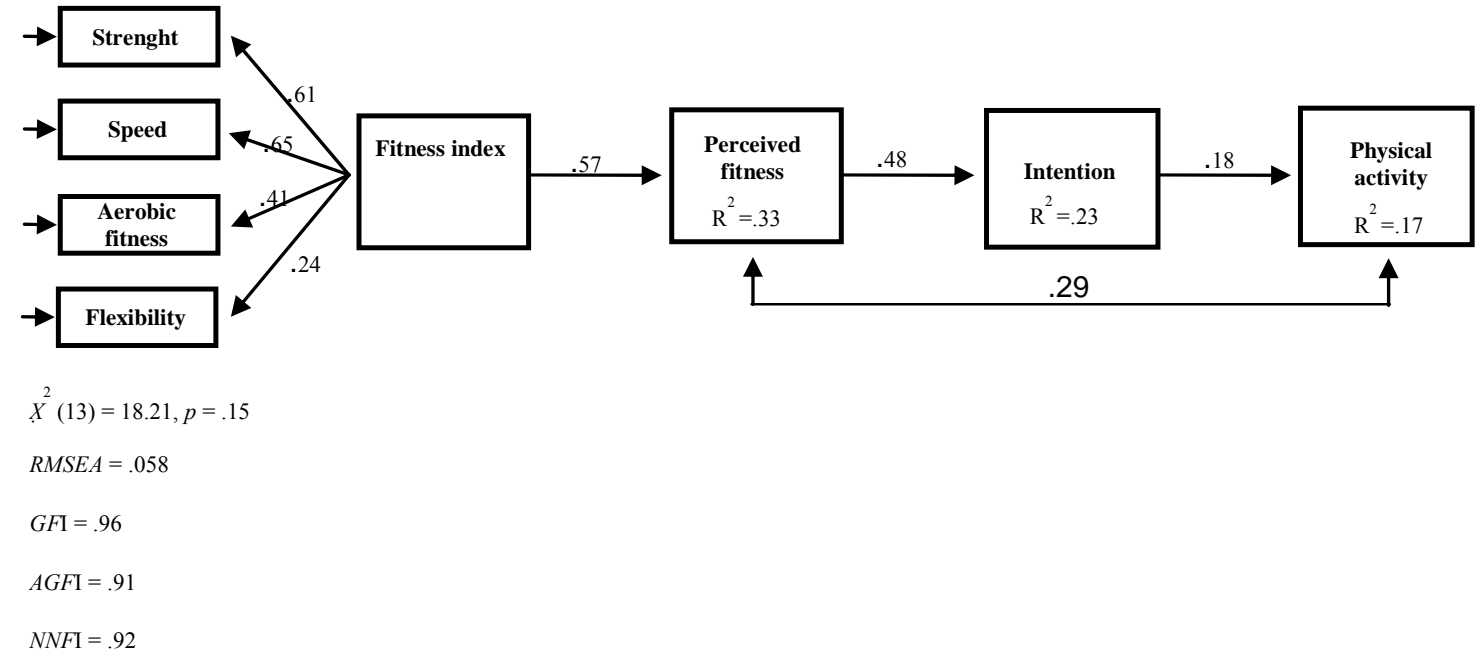

Figure 2.

The results of the Structural Equation Modelling. 


\section{Discussion}

The main purpose of the present study was to investigate the associations among measured physical fitness, perceived fitness, intention towards future PA, and self-reported PA during junior high school years. We hypothesized that actual physical fitness is positively associated with perceived physical fitness at Grade 7. Additionally, we assumed that perceived physical fitness positively and sequentially predicted intention towards PA at Grade 8 and self-reported PA at Grade 9. To our knowledge, this is the first attempt to analyze measured and perceived physical fitness, intention, and self-reported PA through junior high school.

Path analysis revealed an indirect path from physical fitness index to self-reported PA via perceived physical fitness and intention towards future PA. Additionally, analysis indicates a correlation between perceived physical fitness and PA. Although squared multiple correlations among study variables are rather low, the results of the study indicate that both physical and cognitive variables are involved in the process in which adolescents adopt PA.

In this study, physical fitness was associated with later PA as earlier studies have suggested (Malina, 2001). However, physical fitness measured at Grade 7 did not have a direct effect on PA at Grade 9. The path from physical fitness to future PA is through perceived fitness and intention towards future PA. The results of this study highlight the important roles that cognitive factors serve in the process of PA adoption (Hagger \& Chatzisarantis, 2009; Sallis et al., 2000). These results may also explain earlier contradictory findings on the associations between physical fitness and PA, where students with good results in muscular endurance, muscular strength, body composition, and flexibility are not necessarily the most active (Huotari et al., 2009; Huotari et al., 2010; Malina, 2001). The results of this study suggest that cognitive attributes exist between measured physical fitness and PA. Students who score high on fitness tests do not necessarily perceive themselves as competent in the PA domain or have not developed intention towards PA. According to the social cognitive models of behavior, these constructs are crucial for targeting behaviors such as PA (Ajzen, 1991; Bandura, 1997; Hagger et al., 2007). The lack of these cognitive variables is evidenced by students' lower level of engagement in PA.

This study reveals that the perception of one's fitness is a crucial factor shaping a student's intention towards future activity and subsequent PA patterns. This finding is in agreement with many sport psychology studies, which have found positive associations between physical self-perceptions and PA within adolescent groups (Bagoien \& Halvari, 2005; Dishman et al., 2005; Hagger et al., 2003; Sallis et al., 2000; Tremblay, 2000).

The results of this study also further support social cognitive models, which propose that intention mediates between self-perception and behavior (Ajzen, 1991; Hagger \& Chatzisarantis, 2007). Earlier empirical studies in adolescents' PA context have shown contradictory results of these associations. Most studies have supported social cognitive models (Hagger, 2001; Hagger et al., 2003; Hagger et al., 2007; Rhodes, Macdonald, \& McKay, 2006) whereas some have not given support to the models (Motl, 2002). The possible reason for these contradictory results may be that the studies pertaining to social cognitive models were cross-sectional designs or the time interval between measurement points was only few weeks. It is evident that the behavioral change especially in adolescence, where many psychological, social, and physical changes exist, takes more time
(Booth et al., 2010). In this study, we followed students through their 3-year junior high school period, which provides reliable information on the associations among perceived physical fitness, intention, and self-reported PA. Additionally, knowing that PA levels typically decreases during junior high school (Telama \& Yang, 2000; Nader et al., 2008), it was important to investigate the associations among physical, cognitive, and behavioral variables within the junior high school period.

The results of this study highlight the role of measured and perceived physical fitness in the process of adoption of PA in adolescence. Schools and particularly physical education are the obvious possible channels to support engagement in PA as they reach the entire age cohort of adolescents. However, in many countries, the students have only one session of obligatory physical education weekly. Clearly, a single class is not sufficient to develop a students' actual fitness. Therefore, the emphasis concerning physical fitness training in physical education curriculum should include an educational component to address leisure time fitness opportunities. The physical education curriculum could include information on FIT (intensity, time, and frequency) principles, and the benefits of physical fitness training. Earlier studies in adolescents' in PA context have shown that a teacher can contribute to a child's attitude and intention towards PA. For example in 2005, Chatzisarantis and Hagger performed an intervention with schoolchildren that demonstrated children that were in a salient belief-based persuasive communication group reported more positive attitudes and stronger intentions towards future PA than those who were in nonsalient behavioral belief group. These findings suggest that even little investments in physical education curriculum might positively affect the possibility for adolescents PA engagement.

Motivation research in the area of sport and exercise psychology has revealed that self-referenced rather than normative social climate of the PA participation groups have been associated with positive development of physical self-perceptions, PA intentions, and actual PA. In other words, by emphasizing a task-involving motivational climate practitioners are able to positively affect all cognitive and behavioral variables adopted in our study (Standage, Duda, \& Ntoumanis, 2003a; Standage, Duda, \& Ntoumanis, 2003b; Standage, Duda, \& Ntoumanis, 2005; Wallhead \& Ntoumanis, 2004). These results emphasize that when implementing physical fitness training, practitioners should utilize a task-involving motivational climate for example by adopting didactical principles of the TARGET model (Epstein, 1989). In this way he/she is able to support the cognitive and behavioral process where adolescents adopt PA.

The use of self-reports in measuring PA engagement is one of the limitations of this study. In some studies self-report measures of PA have had limited reliability and validity particularly in samples of children and adolescents (Shephard, 2003). Another limitation of this study is a relatively small number of participants. The sample size did not allow for us to compare the boys' and the girls' models with each other. Earlier studies have indicated that there are differences in physical self-perceptions between boys and the girls. For example, Lintunen (1995) recognized that between ages 11 and 15 girls' physical selfperceptions became more realistic compared with the boys perceptions. These differences might also relate to the gender differences in the process of adoption PA. Finally, there are limitations to the study as it is cross sectional in nature with measures taken at three different time points over a span of three years. Therefore, the results can only be interpreted as observed associations between the main variables over a three-year period. 
Future studies should investigate whether gender differences affect the outcome measures. In addition, it will be important for future interventions to implement measures that affect students' intention towards PA through the school years. Such interventions would help inform researchers to understand just how physical and cognitive variables interact while school aged students adopt habitual or lifelong PA.

\section{References}

Ajzen, I. (1991). The theory of planned behavior. Organizational Behavior and Human Decision Processes, 50, 179-211. doi:10.1016/0749-5978(91)90020-T

Bagoien, T. E., \& Halvari, H. (2005). Autonomous motivation: Involvement in physical activity, and perceived sport competence: Structural and mediator models. Perceptual and Motor Skills, 100, 3-21. doi:10.2466/pms.100.1.3-21

Bandura, A. (1997). Self-efficacy: The exercise of control. New York, NY: Freeman.

Booth, M. L., Macaskill, P., Owen, N., Oldenburg, B., Marcus, B. H., \& Bauman, A. (2010). Stages of change in physical activity: A validation study in late adolescence. Health Education \& Behavior, 37, 318-329. doi:10.1177/1090198109333281

Caspersen, C. J., Powell, K. E., \& Christenson, G. M. (1985). Physical activity, exercise and physical fitness: Definitions and distinctions for health-related research. Public Health Reports, 100, 126-31.

Chatzisarantis, N. L. D., \& Hagger, M. S. (2005). Effects of a brief intervention based on the theory of planned behavior on leisure-time physical activity participation. Journal of Sport \& Exercise Psychology, 27, 470-487

Dishman, R. K., Motl, R. W., Sallis, J. F., Dunn, A. L., Birnbaum, A. S., Welk, G. J., Bedimo-Rung, A. L., Voorhees, C. C., \& Jobe, J. B. (2005). Self-management strategies mediate self-efficacy and physical activity. American Journal of Preventive Medicine, 29, 10-18. doi:10.1016/j.amepre.2005.03.012

Epstein, J. L. (1989). Family structures and student motivation: A developmental perspective. In C. Ames and R. Ames (Eds.), Research on motivation in education (pp. 259-295). San Diego, CA: Academic Press.

EUROFIT (1988). Handbook for the eurofit tests of physical fitness. Rome: Committee for the Development of Sport, Council of Europe.

Hagger, M. S., \& Chatzisarantis, N. L. D. (2007). The trans-contextual model of motivation. In M. S. Hagger and N. L. D. Chatzisarantis (Eds.), Intrinsic motivation and self-determination in exercise and sport (pp. 54-70). Champaign, Il: Human Kinetics.

Hagger, M. S., \& Chatzisarantis, N. L. D. (2009). Integrating the theory of planned behavior and self-determination theory in health behavior: A meta-analysis. British Journal of Health Psychology, 14, 275-302. doi:10.1348/135910708X373959

Hagger, M. S., Chatzisarantis, N. L. D., \& Harris, J. (2006). From psychological need satisfaction to intentional behavior: Testing a motivational sequence in two behavioral contexts. Personality and Social Psychology Bulletin, 32, 131-148. doi:10.1177/0146167205279905

Hagger, M. S., Chatzisarantis, N. L. D., Biddle, S. J. H., \& Orbell, S. (2001). Antecedents of children's physical activity intentions and behavior: Predictive validity and longitudinal effects. Psychology and Health, 16, 391-407. doi:10.1080/08870440108405515

Hagger, M. S., Chatzisarantis, N. L. D., Culverhouse, T., \& Biddle, S. J. H. (2003). The processes by which perceived autonomy support in physical education promotes leisure-time physical activity intentions and behavior: A trans-contextual model. Journal of Educational Psychology, 95, 784-795. doi:10.1037/0022-0663.95.4.784

Hagger, M. S., Chatzisarantis, N. L. D., Barkoukis, V., Wang, J. C. K., Hein, V., \& Karsai, I. (2007). Cross-cultural generalizability of the theory of planned behavior among young people in a physical activity context. Journal of Sport \& Exercise Psychology, 29, 1-20.

Harter, S. (1978). Effectance motivation reconsidered: Toward a developmental model. Human Development, 21, 34-64. doi: $10.1159 / 000271574$

Huotari, P., Sääkslahti, A., \& Watt, A. (2009). Associations between the self-estimated and actual physical fitness scores of Finnish Grade
6 students. Facta Universitatis: Series Physical Education and Sport, 7, 27-36.

Huotari, P. R. T., Nupponen, H., Laakso, L., \& Kujala, U. M. (2009). Secular trends in aerobic fitness performance in 13-18-year-old adolescents from 1976 to 2001. British Journal of Sports Medicine, 44, 968-972. doi:10.1136/bjsm.2008.055913

Huotari, P. R. T., Nupponen, H., Laakso, L., \& Kujala, U. M. (2010). Secular trends in muscular fitness among Finnish adolescents. Scandinavian Journal of Public Health, 38, 739-747. doi:10.1177/1403494810384425

Larson, L. A. (1974). Fitness, health, and work capacity. International standards for assessment. New York, NY: Macmillan.

Lintunen, T. (1995). Self-perceptions, fitness, and exercise in early adolescence: A four-year follow-up study. Studies in Sport, Physical Education and Health no. 41. Jyväskylä: University of Jyväskylä.

Lippke, S., Ziegelmann, J. P., \& Schwarzer, R. (2004). Behavioral intentions and action plans promote physical exercise: A longitudinal study with orthopaedic rehabilitation patients. Journal of Sport and Exercise Psychology, 26, 470-483.

Malina, R. (2001). Physical activity and fitness: Pathways from childhood to adulthood. American Journal of Human Biology, 13, $162-172$.

doi:10.1002/1520-6300(200102/03)13:2<162::AID-AJHB1025>3.0. $\mathrm{CO} ; 2-\mathrm{T}$

Motl, R. W., Dishman, R. K., Saundres, R. P., Dowda, M., Felton, G., Ward, D. S., \& Pate, R. R. (2002). Examining social-cognitive determinants of intention and physical activity among Black and White adolescent girls using structural equation modelling. Health Psychology, 21, 459-467. doi:10.1037/0278-6133.21.5.459

Nader, P. R., Bradley, R. H., \& Houts, R. M. (2008). Moderate-to-vigorous physical activity from ages 9 to 15 years. Journal of American Medical Association, 300, 295-305.

doi:10.1001/jama.300.3.295

Nupponen, H., Soini, H., \& Telama, R. (1999). Koululaisten kunnon ja liikehallinnan mittaaminen. [Measurement of school students' physical fitness and motor skills] Research Reports on Sport and Health 118. Jyväskylä: Research Center for Sport and Health Sciences.

Prochaska, J. J., Sallis, J. F., \& Long, B. (2001). A physical activity screening measure for the use with adolescents in primary care. $A r$ chives in Pediatric Adolescence Medicine, 155, 554-559.

Rhodes, R. E., Macdonald, H. M., \& McKay, H. A. (2006). Predicting physical activity intention and behavior among children in a longitudinal sample. Social Science \& Medicine, 62, 3146-3156. doi:10.1016/j.socscimed.2005.11.051

Safrit, M. J. (1990). The validity and reliability of fitness tests for children: A review. Pediatric Exercercise Science, 2, 9-28.

Sallis, J. F., Prochaska, J. J., \& Taylor, W. C. (2000). A review of correlates of physical activity of children and adolescents. Medicine and Science in Sports and Exercise, 32, 963-975. doi:10.1097/00005768-200005000-00014

Shephard, R. J. (2003). Limits to the measurement of habitual physical activity by questionnaires. British Journal of Sports Medicine, 37, 197-206. doi:10.1136/bjsm.37.3.197

Standage, M., Duda, J. L., \& Ntoumanis, N. (2003a). Predicting motivational regulations in physical education: The interplay between dispositional goal orientations, motivational climate and perceived competence. Journal of Sports Sciences, 21, 631-647. doi:10.1080/0264041031000101962

Standage, M., Duda, J. L., \& Ntoumanis, N. (2003b). A model of contextual motivation in physical education: Using constructs from self-determination and achievement goal theories to predict physical activity intentions. Journal of Educational Psychology, 95, 97-110. doi:10.1037/0022-0663.95.1.97

Standage, M., Duda, J. L., \& Ntoumanis, N. (2005). A test of selfdetermination theory in school physical education. British Journal of Educational Psychology, 75, 411-433. doi:10.1348/000709904X22359

Telama, R., \& Yang, X. (2000). Decline of physical activity from youth to young adulthood in Finland. Medicine and Science in Sports and Exercise, 32, 1617-1622. doi:10.1097/00005768-200009000-00015

Telama, R., Yang, X., Viikari, J., Välimäki, I., Wanne, O., \& Raitakari, O. (2005). Physical activity from childhood to adulthood: A 21-year tracking study. Americal Journal of Preventive Medicine, 3, 267-273. 
doi:10.1016/j.amepre.2004.12.003

Tremblay, M. S., Inman, J. W., \& Willms, J. D. (2000). The relationship between physical activity, self-esteem, and academic achievement in 12-Year-Old Children. Pediatric Exercise Science, 12,
312-323.

Wallhead, T. L., \& Ntoumanis, N. (2004). Effects of a sport education intervention on students' motivational responses in physical education. Journal of Teaching in Physical Education, 23, 4-18. 